\title{
Bayesian hierarchical analyses for entrepreneurial intention of students
}

\author{
Mesfin Mulu Ayalew* (D)
}

\section{${ }^{*}$ Correspondence:}

m2mulu@gmail.com Bahir Dar University, Bahir Dar Institute of Technology, Bahir Dar, Ethiopia

\begin{abstract}
In recent years, entrepreneurship has become an important issue due to national economic development and the contribution of society. Data with a hierarchical structure received more attention and occur frequently in social science, public health and epidemiological researches. In such research, binary outcomes are common. Multilevel logistic regression models allow one to account for the clustering of subjects within clusters of higher-level units when estimating the effect of subject and cluster characteristics on subject outcomes. Traditional logistic regression is inappropriate when data are hierarchically structured. Therefore, this study presents multi-level Bayesian logistic analysis for entrepreneurial intention of students using classical and Bayesian approach. The descriptive result revealed that about $57.4 \%$ of the students had an entrepreneurial intention while $42.6 \%$ do not have an intention. The results also showed that entrepreneurial education/training and entrepreneurial attitudes significantly predicts students' entrepreneurial intention at $5 \%$ level of significance. The model results indicate that the effects of the selected variable on entrepreneurial intention vary across university. By failing to take into account the clustering within university (level 2), Bayesian multilevel effects are not taken into consideration in modeling, the $\beta$ coefficients in multilevel logistic model using classical approach are distorted somewhat in both directions either in over or under direction. This study also evaluates and compares the behavior of maximum likelihood and Bayesian estimators to investigate the relationship between covariates and the response. Both point and interval estimation performances were investigated. The results revealed that lower standard errors of the estimated coefficients in the Bayesian logistic regression approach as compared to classical approach. Moreover, the results revealed that the length of the Bayesian credible interval is smaller than the length of the maximum likelihood confidence interval for all factors. In order to identify the most plausible method between Bayesian method and maximum likelihood estimation of the data, AIC, BIC and DIC are adopted in this paper. The result of the study depicts that the Bayesian method performs better and more efficient than maximum likelihood estimation. The study recommends that the government as well as the universities should design programs that facilitate entrepreneurship to change the mindset, attitude, and intention of those students who do not have knowhow about entrepreneurship as a future career.
\end{abstract}

Keywords: Multilevel analysis, Hierarchical models, Bayesian approach, Cluster data, Entrepreneurial intention, Students 


\section{Introduction}

In recent years, entrepreneurship has become an important issue due to national economic development and the contribution of society. It is rendered by the emergence of new and innovative business start-ups. This new and innovative business idea is developed by entrepreneurs. An entrepreneur is a person who creates new business by taking risks and uncertainties in order to gain some benefits and growth in business by identifying the opportunities and combining different resources required to establish the new business [47]. The decision as an entrepreneur is determined by certain factors, it is a planned action, instead of using it by mistake. In general, entrepreneurial intent is defined as a mindset that directs a person's attention and action towards supporting entrepreneurial behavior, developing a new business concept, and pursuing entrepreneurial careers.

Students may have different attitude and can react differently on the expected entrepreneurial behavior. Perhaps they can exhibit positive or negative attitude toward entrepreneurship depending on their background and other traits. If the students have positive attitudes toward entrepreneurship, it is likely that after graduation they will start their own business. Conversely, if they form negative attitude, likely they will not become self-employed. In general, individuals desiring more income, more independence, and more net perquisites have high tendency to engage in entrepreneurship [14].

Unemployment occurs due to many factors, one of them is because of the limitation of job opportunities. Nowadays, many college graduates prefer to work as employee in a company or becoming government employee. It means that they are a job seeker instead of a job creator. Only few of them think to create self-employment or become entrepreneur due to lack of confidence in their skill and capital [21]. Other researchers pointed out that an individual with higher tolerance for risk and less aversion to work effort should be expected to be more likely to engage in entrepreneurial behavior $[3,5,11]$.

Many studies on college students' intention to become entrepreneur have been conducted. Scholars are trying to identify the contributing risk factors of student's entrepreneurial intention for their future career. The willingness in becoming entrepreneurship are determined by some other factors such as family, motivation, risk taking propensity or the courage to take a risk, and self-concept as individual factor [4, 21, 44]. Family environment and all conditions within its family including how parents educate, family member's relation, house condition, family's financial condition, parents understanding, and cultural background will support, guide, and encourage children to their future life. This is consistent with a research done by Lindquist et al. [29], Fatoki [13] whom states that family environment gives positive influence on the willingness in entrepreneurship. Social factors have also an encouraging or impeding effect on the intention of individuals for entrepreneurial career. Family background, education, previous work experience, risk attitude, over-optimism, preference for independence, and the norms and values of a society influence the choice of individual's life careers, i.e., entrepreneurship or salaried employment [41].

Nguyen [34] also studied entrepreneurial intention among international business students in Viet Nam. The result of the study confirms that attitude towards entrepreneurship and perceived behavior control is positively related to entrepreneurial intention. On the contrary, subjective norm fails to generate a significant impact on entrepreneurial 
intention. A research done by Kristiansen and Indarti [27] also pointed out that access to information and finance are also an important element for the intention to establish a new business. This may be achieved through effective communication whereby information is captured properly and feedback is provided. High achievements on creativity and prior entrepreneurial experiences have also a direct relationship with entrepreneurial preferences, whereas perception of failure has an indirect influence $[9,20,35]$.

Educational support through professional education in universities is an efficient way of obtaining necessary knowledge about entrepreneurship [3]. The study by Autio et al. [2] that investigated entrepreneurial intention of university students in various cultural contexts indicated that the encouragement from university environment affects the entrepreneurial confidence of university students. This is supported by the study done by Wang and Wong [45] who pointed out that entrepreneurial dreams of many students are hindered by inadequate preparation of the academic institution. The school and education system also play a critical role in identifying and shaping entrepreneurial traits [25]. Other studies have pointed out that entrepreneurship education, especially education that provides technological training, is crucial to enhance entrepreneurs' innovation skills in an increasingly challenging environment $[15,16,28]$. They stated in their research as proper entrepreneurship education exposure will enables students to have positive attitudes towards choosing entrepreneurship as a career.

Data with a hierarchical structure received more attention and occur frequently in social science, public health and epidemiological researches. These hierarchical structured data are characterized by so-called "nested" membership relations among the units of observation. For instance, in social and behavioral science research, employees are nested within departments, residents clustered within neighborhoods, workers clustered within workplaces, sportsmen are nested within teams, etc. Classic examples of hierarchical data are also found in educational research: students are nested within classes, which are nested within schools/universities. In longitudinal/repeated measures research, data collected at different times and under different conditions are nested within each study participant $[36,39]$. Many other examples can be imagined. These hierarchically structured data can be modelled using hierarchical models. Hierarchical models are statistical models that can be used to analyze nested sources of variability in hierarchical data, taking account of the variability associated with each level of the hierarchy. These models have also been referred to as multilevel models, mixed models, random coefficient models, and covariance component models [6, 19, 24, 30, 42].

Previous studies have shown variables that might affect entrepreneurial intention at individual level (single level) using linear and/or binary regression models. But the data we considered for this research has a hierarchical structure, i.e., students are clustered within university. Traditional "single level" models fail when data are hierarchically structured, because the assumption of independence of observations conditional on the explanatory variables is violated. The nested structure causes so called "intraclass dependency" among the observations within units at the higher level of the hierarchy. The hierarchical 1 logistic regression analysis considers the variations due to hierarchy structure in the data. It allows the simultaneous examination of the effects of group level and individual level variables on outcomes while accounting for the non-independence of observations within groups. Also, this analysis allows the examination of both 
between group and within group variability as well as how group level and individual level variables are related to variability at both levels.

The area of this study covers behavioral, attitudinal and educational support factors and how these influences the intentions of students to become entrepreneurs using hierarchical models. Therefore, the objectives of this study are (1) to identify critical factors influencing the entrepreneurial intention of students after graduation at individual level and higher levels, (2) to examine to what extent these factors influence student's entrepreneurial intention (3) to compare the classical and Bayesian approach with noninformative prior for the estimations of model parameters.

\section{Methods}

\section{Research design}

This study was carried out through a survey method using questionnaires as the main instrument.

\section{Sample}

The population for this study was final year undergraduate engineering students in Bahir Dar University (BDU), Debre Markos University (DMU) and University of Gondar (UoG) in Ethiopia in 2016/2017 academic session. These groups of students were chosen because they were suitable to conduct a research on entrepreneurial intention of students as they were facing important career decisions on completion of their studies, of which entrepreneurship could be one of them. In this research, stratified sampling technique was employed and the required sample size for each university and departments was determined by Yamane [46] and Cochran's [7] equations at 5\% level of precision respectively. The study involved 921 final year university students who were registered for various engineering degrees in 2016/2017 academic session.

\section{Variables of the study}

The response variable of this study was entrepreneurial intention of students. The data have a hierarchical structure, with students nested within universities. For the purpose of this study, the response variable classified students as who have entrepreneurial intention and who do not have intention. The predictor variables of the study are student-level variables (entrepreneurial attitudes, demographic, and socio-economic characteristics) and university-level variables. The response variable (intention) and some predictor variables (especially attitude) of respondents are measured by providing a 5-point Likert scaling statements ranging from strongly disagree to strongly agree. The list of predictor variables used in this study are presented in Table 1.

\section{Model specification}

The analytical method used in this research is multilevel binary logistic regression model with two levels. In this research, we considered three multilevel regression models.

\section{Empty model}

The empty two-level model for a dichotomous outcome variable refers to a population of groups (level-two units, i.e., university) and specifies the probability distribution 
Table 1 Description of predictor variables

\begin{tabular}{|c|c|c|c|}
\hline S. no. & Variables & Description of variables & Code/level of categories \\
\hline 1. & IOS & $\begin{array}{l}\text { Information and opportunity seeking factor } \\
\text { score }\end{array}$ & None \\
\hline 2. & CPS & $\begin{array}{l}\text { Creativity and problem-solving skill factor } \\
\text { score }\end{array}$ & None \\
\hline 3. & AIR & $\begin{array}{l}\text { Achievement and instrumental readiness } \\
\text { factor score }\end{array}$ & None \\
\hline 4. & DEE & $\begin{array}{l}\text { Discouragement by external environment } \\
\text { factor score }\end{array}$ & None \\
\hline 5. & SCSE & Self-confidence and self-esteem factor score & None \\
\hline 6. & GS & Goal setting factor score & None \\
\hline 7. & SP & Systematic planning factor score & None \\
\hline 8. & BOF & Business owned family & $1=y e s, 2=$ no \\
\hline 9. & PBE & Previous business experience with family & $1=$ yes, $2=$ no \\
\hline 10. & $\mathrm{BOC}$ & Business owned colleague & $1=$ yes, $2=$ no \\
\hline 11. & AF & Access to finance/capitals & $1=$ yes, $2=$ no \\
\hline 12. & IG & Information gathering & $1=y e s, 2=$ no \\
\hline 13. & CFBI & Clear future business ideas & $1=y e s, 2=$ no \\
\hline 14. & RTC & Risk taking commitment for a career decision & $1=y e s, 2=$ no \\
\hline 15. & N_E & Networking with entrepreneurs & $1=$ yes, $2=$ no \\
\hline 16. & NERK & No. of entrepreneurs respondents know & $\begin{array}{l}\begin{array}{l}1=\text { not at all, } 2=\text { less than } 2,3=2 \text { up to } 4 \\
4=\text { above } 4\end{array}\end{array}$ \\
\hline 17. & $\mathrm{PO}$ & Parents occupation & $\begin{array}{l}1=\text { agriculture, } 2=\text { gov't employee, } 3=\text { pri- } \\
\text { vate business owned, } 4=\text { others }\end{array}$ \\
\hline 18. & MFSB & Means of finance for a career business & $\begin{array}{l}1=\text { family }, 2=\text { colleague, } 3=\text { micro finance } \\
4=\text { inheritance, } 5=\text { others }\end{array}$ \\
\hline 19. & $\mathrm{EE}$ & Entrepreneurship education/trainings & $1=y e s, 2=$ no \\
\hline 20. & $\mathrm{BC}$ & Business counselling & $1=$ yes, $2=$ no \\
\hline 21. & SBIE & $\begin{array}{l}\text { Sharing of business ideas and experiences by } \\
\text { invited guests }\end{array}$ & $1=$ yes, $2=$ no \\
\hline
\end{tabular}

Reference category is the last category for each categorical variable

for group-dependent probabilities without taking further explanatory variables into account. This model only contains random groups and random variation within groups. It can be expressed with logit link function as follows.

$$
\operatorname{Pr} .\left(Y_{i j}=1\right)=\operatorname{logit}^{-1}\left(\beta_{0}+\emptyset_{0 j}\right)
$$

where $\left.\emptyset_{0 j} \sim I I D\left(0, \sigma_{\emptyset}^{2}\right)\right), \sigma_{\emptyset}^{2}$ is the variance in the population distribution, and therefore the level of heterogeneity of observations in the data structure and $\emptyset_{0 j}$ is the random deviation from this average for group $j$. It means that the random effect of being in group $j$ on its within observations (on the log-odds that $Y=1$ ); also known as a level 2 residual.

\section{Fixed-effect model}

The fixed effects binary logistic regression for two-level model for data obtained from $N$ individuals (students), nested within $J$ groups (universities), each containing $N_{J}$ individuals, is specified as follows. For each group $j(j=1,2 \ldots J)$, the Level-1 or within-group model is given by: 


$$
\operatorname{Pr} .\left(Y_{i j}=1\right)=\operatorname{logit}^{-1}\left(X^{\prime} \beta+\emptyset_{0 j}\right)
$$

where $\emptyset_{0 j} \sim \operatorname{IID}\left(0, \sigma_{\emptyset}^{2}\right)$, $\mathrm{Y}$ is an $\mathrm{N} \times 1$ a vector of observations for the response variable, $\mathrm{X}$ is an $\mathrm{N} \times \mathrm{K}$ matrix of fixed effect predictors, $\beta$ is a $\mathrm{K} \times 1$ vector of fixed effect regression coefficients, $\emptyset_{0 j}$ is the effect of being in group $\mathrm{j}$ on the log-odds that $\mathrm{Y}=1$; also known as a level-2 residual, $\sigma_{\emptyset}^{2}$ is the level-2 (residual) variance, or the between-group variance in the $\log$-odds that $\mathrm{Y}=1$ after accounting for $\mathrm{X}$.

\section{Random effect model}

It is well known that the entrepreneurial intention of students in the same university are likely to be clustered due to the influence of unmeasured university characteristics like university leadership, delivery of entrepreneurship-oriented education system, training facilities, business counselling, etc. A common way to allow for such university effects on students' entrepreneurial intention is to fit a hierarchical regression model with a two-level nested structure in which students (at level 1) are grouped within university (at level 2).

Let $Y_{\mathrm{ij}}$ denote the binary response variable measured on the ith subject within the jth cluster $\left.\left(i=1 \ldots N_{j} ; j=1 \ldots\right)\right) . \mathrm{Y}_{\mathrm{ij}}=1$ denotes success or the occurrence of the event, while $Y_{i j}=0$ denotes failure or lack of occurrence of the event. Furthermore, let $X_{1 i j}$, through $X_{k i j}$ denote the $\mathrm{k}$ fixed effect predictor or explanatory variables measured on this subject (i.e., students' characteristics). Finally, let $\mathrm{Z}$, through $\mathrm{Z}_{\mathrm{mj}}$ denote the $\mathrm{m}$ random effect predictor variables measured on the jth cluster (i.e., university characteristics). Now, the model is specified as follows.

$$
\operatorname{Pr} .\left(Y_{i j}=1\right)=\operatorname{logit}^{-1}\left(X^{\prime} \beta+Z^{\prime} \alpha+\emptyset_{0 j}\right)
$$

where $\emptyset_{0 j} \sim I I D\left(0, \sigma_{\emptyset}^{2}\right), \mathrm{Y}$ is an $\mathrm{N} \times 1$ a vector of observations for the response variable, $\mathrm{X}$ is an $\mathrm{N} \times \mathrm{K}$ matrix of fixed effect predictors, $\beta$ is a $\mathrm{K} \times 1$ vector of fixed effect regression coefficients, $\mathrm{Z}$ is an $\mathrm{N} \times \mathrm{m}$ matrix of random effect predictors, $\alpha$. is an $\mathrm{m} \times 1$ vector of random effect regression coefficients and $\emptyset_{0 j}$ is an $\mathrm{N} \times 1$ vector of observation for random error terms.

\section{Estimation techniques}

In this paper, maximum likelihood and Bayesian estimation methods are used for estimating the fixed components and variances of the random components in hierarchical models.

Classical approach: Classical inference supposes that the model parameters are fixed, though they are unknown and that the data are random.

For a sample of size $\mathrm{n}$ whose observations are $\mathrm{y} 1, \mathrm{y} 2, \ldots, \mathrm{yn}$, the corresponding random variables are Y1, Y2, ...,Yn. From a distribution with vector of parameter $\theta$ (unknown parameter $\beta$ and $\emptyset_{0 j}$.) The conditional probability that the outcome is present (probability of success), $\pi_{i}\left(x_{i}\right)$, given for parameters $\theta$ and explanatory variables $x_{i}$. is given by

$$
\pi_{i}\left(x_{i}\right)=P(Y=1 / X, \theta)=\frac{\exp \left(X^{\prime} \beta+\emptyset_{0 j}\right)}{1+\exp \left(X^{\prime} \beta+\emptyset_{0 j}\right)}
$$

Since $\mathrm{Yi}$ is a Bernoulli random variable, for a give parameter $\theta$ the probability of the observed data $(\mathrm{Y})$ can be written as: $\mathrm{P}(\mathrm{Y} \mid \theta))$. 


$$
P_{i}\left(y_{i}\right)=\pi_{i}^{y_{i}}\left(1-\pi_{i}\right)^{1-y_{i}}
$$

where $\mathrm{Yi}=1$ or 0 and $\mathrm{i}=1,2 \ldots, \mathrm{n}$. If $\mathrm{Yi}=1$, then the ith student have entrepreneurial intention and if $\mathrm{Yi}=0$, it means that the ith student don't have an intention.

Since the observations are assumed to be independent, the likelihood function is obtained by as the product of the terms given in Eq. (5) as follows.

$$
l(\theta)=P(Y / \theta, X)=\prod_{i=1}^{n} \pi\left(x_{i}\right)^{y_{i}}\left[1-\pi\left(x_{i}\right)\right]^{1-y_{i}}
$$

Equation (6) can be written as:

$$
l(\theta)=P(Y / \theta, X)=\prod_{i=1}^{n}\left(\frac{\exp \left(X^{\prime} \beta+\emptyset_{0 j}\right)}{1+\exp \left(X^{\prime} \beta+\emptyset_{0 j}\right)}\right)^{y_{i}}\left(1-\frac{\exp \left(X^{\prime} \beta+\emptyset_{0 j}\right)}{1+\exp \left(X^{\prime} \beta+\emptyset_{0 j}\right)}\right)^{\left(1-y_{i}\right)}
$$

$l(\theta)$ is called the likelihood function for $\theta$. Since the same value maximizes both $l(\theta)$ and $\log (l(\theta))$, it is more convenient or easier mathematically to work with the log-likelihood function which is given by:

$$
L(\theta)=\ln [l(\theta)]=\sum_{i=1}^{n} y_{i} \ln \left(\frac{\pi_{i}}{1-\pi_{i}}\right)+\sum_{i=1}^{n} \ln \left(1-\pi_{i}\right)
$$

where $\pi_{i}\left(x_{i}\right)$ is given in Eq. (4)

To find the maximum likelihood estimates of $\theta$, differentiate Eq. (8) with respect to $\theta$ and setting the result to 0 gives

$$
\sum_{i=1}^{n}\left\lceil y_{i}-\pi\left(x_{i}\right)\right\rceil=0
$$

And

$$
\sum_{i=1}^{n} x_{i j}\left[y_{i}-\pi\left(x_{i}\right)\right\rceil=0
$$

No closed form solution exists for this maximization procedure for the value of maximum likelihood estimates of $\theta$. Therefore, a Newton-Raphson iterative reweighted least square algorithm procedure such as expectation maximization or fisher scoring is used for the estimation purpose.

Maximum likelihood estimation yields simultaneous estimation of fixed and random components by maximizing the likelihood function of the data [8]. These estimates are those parameter values that were most likely to have produced the observed data [32]. Maximum likelihood works well when sample sizes are large and when there are many groups at the second level. However, when either or both of these are small, the variances are negatively biased [38, 39]. To account for these limitations, MCMC can be employed.

Bayesian approach: Bayesian inference assumes that the data are fixed and considers all unknown parameters as random variables. If we consider a given parameter $\theta$ 
and a set of observed data, the Bayesian approach will be interested in the probability of the parameter $\theta$ given the set of data available $y$, mathematically this can be written as: $\mathrm{P}(\theta \mid \mathrm{Y})$.

Bayesian framework considers three key components for parameter estimation: the prior distribution, the likelihood function, and the posterior distribution. The prior distribution models the prior belief that each possible parameter value is true before the analysis of new data. The prior belief can be specified based on previous research or expert opinion. The likelihood function is the likelihood of parameter values based only on the data collected in a given study. This is the same likelihood as was maximized using Maximum likelihood in the classical approach. The posterior models the probability of each possible parameter value being true, given the prior and likelihood. The posterior probability distribution is obtained mathematically by combining the prior and the likelihood with the use of Bayes' Theorem.

In Bayesian inference, the prior information can be informative or non-informative prior. A prior information is said to be informative prior if there is a solid external information about the distribution of the parameter of interest while non-informative are used in the case where no solid scientifically sound prior information is available about the parameter of interest. The use of an informative prior is justified when evidence exists indicating that certain parameter values are more likely to be true than others. Instead of assigning equal credibility for all values a priori, an informative prior can be used to assign higher credibility to values that have been found in the literature or are deemed more reasonable by experts.

Since this research work has no solid scientifically sound prior information about the parameter of interest, as a result this research work uses non-informative priors. We choose mean zero and standard deviation 100 . Such a broad distribution gives nearly equal credibility to all possible (and impossible) parameter values. After a prior has been specified and the information from it and the likelihood have been combined, the posterior distribution is used for estimation. From the posterior distribution, point and interval estimates are determined.

Mathematically, Bayesian inference was formulated as follows. The parameters $\theta$ are unknown and thus have their own prior distribution, $\mathrm{P}(\theta)$. The prior distribution is [17] is defined as

$$
P\left(\theta_{j}\right)=\frac{1}{\sqrt{2 \pi \sigma_{j}^{2}}} \exp \left\{\frac{-1}{2}\left(\frac{\theta_{j}-\mu_{j}}{\sigma_{j}}\right)^{2}\right\}
$$

and the posterior distribution, $\mathrm{P}(\theta / Y)$, can be obtained by mathematically combining the likelihood and prior with the use of Bayes' Theorem. The result is as follows.

$$
\begin{aligned}
\mathrm{P}(\theta / y) \propto P(y / \theta) * P(\theta)= & \prod_{i=1}^{n}\left(\frac{e^{X^{\prime} \beta+\emptyset_{0 j}}}{1+e^{X^{\prime} \beta+\emptyset_{0 j}}}\right)^{y_{i}}\left(1-\frac{e^{X^{\prime} \beta+\emptyset_{0 j}}}{1+e^{X^{\prime} \beta+\emptyset_{0 j}}}\right)^{\left(1-y_{i}\right)} \\
& * \frac{1}{\sqrt{2 \pi \sigma_{j}^{2}}} \exp \left\{\frac{-1}{2}\left(\frac{\theta_{j}-\mu_{j}}{\sigma_{j}}\right)^{2}\right\}
\end{aligned}
$$


The parameters of the fixed and random components were estimated based on Markov Chain Monte Carlo (MCMC) simulation techniques using Random-walk MetropolisHastings sampling. Samples from the posterior distribution are repeatedly taken, creating a distribution of sampled values. The samples are then compiled into a distribution used as the posterior. The sampling process starts with a single value and iteratively converges to the posterior. Multiple starting values are used to produce separate "chains" of resampling. These chains are then combined after thousands of iterations. With enough samples the empirical posterior will approach the mathematical posterior. To determine if enough sampling has occurred, visually monitoring the chains for convergence is recommended. This is accomplished by plotting the sampled values of each chain. If the all values fall within a consistent range, then convergence to the posterior distribution has been achieved. As a result of sampling variability within chains, parameter estimates for the exact same data may not be identical if the same analysis is conducted again. For each model, three chains of 12,500 iterations were set up in the software and 2500 iterations were used in the burn-in step. Convergences of the models were checked by monitoring the MCMC trace plots (time series, Density, autocorrelation, Gelman Rubin) for the model parameters: if all values were within a zone without strong periodicities or tendencies, the model was considered convergent.

\section{Model selection}

In order to select best model among a set of candidate models, Akaike Information Criterion (AIC), Bayesian Information Criterion (BIC) and Deviance Information Criterion (DIC) were applied as the model performance evaluation measure. A smaller AIC, BIC and DIC indicate a better model fitting $[1,22,23]$. The formulae for each evaluation measure are given as follows.

$$
\begin{aligned}
& A I C=-2 / n(L L)+2 k / n \\
& B I C=-2 L L+\ln (n) * k \\
& D I C=-2 L L+C
\end{aligned}
$$

where $\mathrm{n}$ is the number of observations in the dataset, $\mathrm{K}$ is the number of unknown parameters in the model, LL is loglikelihood of the model and $\mathrm{C}$ is a constant that cancels out in all calculations that compare different models, and which therefore does not need to be known.

\section{Results and discussion}

\section{Descriptive results}

As mentioned previously, this study involved 921 final year undergraduate university students who enrolled in various engineering programs. The descriptive result revealed that about $57.4 \%$ of the students have an entrepreneurial intention while $42.6 \%$ do not have. From the sample of respondents, $56.94 \%$ of females do have entrepreneurial intention and $59.07 \%$ of males do have entrepreneurial intention. Based on entrepreneurship training/courses, $59.77 \%$ of the students who took entrepreneurship and businessrelated courses/training do have entrepreneurial intentions. Those respondents who 
made networks with entrepreneurs (61.81\%) have intentions to start business in their future careers. The distribution of student's family occupation is also different in terms of entrepreneurial intention. That is, $63.54 \%$ of the students in which their families are governmental employee have an entrepreneurial intention. Most of the students do not have any exposure to business. $61.22 \%$ of the respondents who tried their own business before have an entrepreneurial intention. Similarly, $61.11 \%$ of the students who came from families who currently run their own business have an intention to engage in entrepreneurial activity. The respondents also breakdown in terms of whether or not they have capital access; $61.33 \%$ of the students who have access to finance have an intention to start business. The majority of students are risk takers. From this risk takers, $60.11 \%$ of them have an entrepreneurial intention. The majority of students who have clear ideas what kind of business they want to do in the future (61.64\%) have entrepreneurial intention. Similarly, $61.33 \%$ of the respondents who gather information about business have an entrepreneurial intention. Moreover, higher percentage (64.8\%) of respondents who know number of entrepreneurs have an intention to engage in entrepreneurial activity.

\section{Reliability and factor analysis}

The internal consistency of the questionnaire was checked from the collected data in pilot study. Exploratory factor analysis was performed separately on the dimensions of students' entrepreneurial intention (dependent variable) and entrepreneurial attitudes (predictor variables). The extraction method used for exploring factors is principal component analysis (PCA). Those factors in which their Eigen values greater than one are retained in the analysis.

The validity and adequacy of the questionnaire was checked by The Kaiser-MayerOlkin (KMO) and Bartlett's Test of Sphericity statistics. The KMO measure of sampling adequacy for the dimension of intention and attitude was 0.885 and 0.947 respectively which indicates that the sample is adequate. A KMO value greater or equal to 0.70 is considered as adequate [31]. The Bartlett's Test of Sphericity for intention and attitude $\left(x^{2}=2295.047\right.$ and $\left.-13,322.545\right)$ respectively was also significant at $5 \%$ level. This value of KMO and Bartlett's Test of Sphericity statistic shows us the appropriateness to apply exploratory factor analysis for the statements of response variable and predictor variables.

The reliability was checked by using Chronbanch's alpha statistics. The value of this statistic is 0.917 that is greater than the minimum acceptable value of 0.70 . This indicates that the data is reliable and can be concluded that the items used for each component measuring entrepreneurial attitudes and intention were assessed to be reliable. For the details of this part (PCA), please refer the first publication by Ayalew and Zeleke [3].

\section{Fitted multilevel logistic regression models}

We fit three multilevel logistic regression models. The first was the null model which did not have any student or university characteristics. It incorporated only universityspecific random effects to model between-university variation in entrepreneurial intention (Model 1). The second model included the student characteristics described above in addition to university-specific random effects (Model 2). The third model included both student characteristics and university characteristics described above in addition to university-specific random effects (Model 3). 


\section{Null model (Model 1)}

We first fit a simple model with no predictors i.e., an intercept-only model that predicts the probability of students' entrepreneurial intention. The estimates of parameters and standard errors are presented in Table 2. The ML estimate from the standard logit model of the ratio of a student who have entrepreneurial intention to who don't have intention is $\exp (0.306)=1.361$, which is the same as the sample ratio of the number of students who have entrepreneurial intention to who don't have. It is in fact odds-ratio when no predictors have been considered in the model. In comparison, the same ratio is estimated to be $\exp (0.3295)=1.39$ and $\exp (0.3271)=1.387$ from the multilevel model by the ML and MCMC methods respectively.

A crude comparison has been made to understand the multilevel effects. Compared to the odds-ratios obtained by all multilevel methods the standard logistic model odds-ratio has underestimated. It is observed that there is a significant difference between the standard logistic estimate and the multilevel logistic estimate. Therefore, by failing to take into account the clustering within university (level 2), the standard logistic model has underestimated the odds-ratio by about 7\% [ $(0.306-$ $0.3295) * 100 / 0.3295$ ] and $6.5 \%$ compared to multilevel model using by the corresponding methods ML and MCMC (see Table 2).

In Table 2, the estimated intercept was 0.3295 , while the estimated variances of the random effect were 0.2929 . Thus, at an average university (i.e., a university whose random effect was equal to zero on the logit scale), the probability of entrepreneurial intention was $\exp (0.3295) /[1+\exp (0.3295)]=0.58$. The $95 \%$ probability interval for the university-specific intercepts is $(0.0949,0.4909)$ (i.e., $95 \%$ of university will have a random intercept that lies within this interval). The estimated variance (unobserved heterogeneity) of the random intercepts using ML and MCMC are 0.2929 (Std. Error 0.1010 ) and 0.2809 (std. error 0.0975) respectively. Both estimates are significantly different from zero and indicate considerable heterogeneity in entrepreneurial intention with respect to students and university that is unaccounted for by the predictor variables and should be adjusted for an adequate analysis.

\section{Fixed effect model (Model 2)}

In this model, student level variables were included in the model to determine the effect of each predictor variables on students' entrepreneurial intention. The results were presented in Table 3.

In the model consisting of student-level variables or characteristics (Model 2), 10 of the 18 student characteristics were significantly associated with the odds of their entrepreneurial intention (Table 3). In the meanwhile, parents' occupation, systematic planning, colleagues' business background, means of finance, discouragement by external environment, risk taking commitment, number of entrepreneurs' respondents knows and clear future business idea are not significant predictors at $5 \%$ level of significance.

The intercept for this model was 0.2570 . Thus, at an average university (i.e., a university whose random effect was equal to zero), the probability of entrepreneurial intention for a student whose covariates were equal to zero was $\operatorname{expo}(0.2570) /[1+\operatorname{expo}(0.2570)]=0.564$. In Table 3 , the variance component 


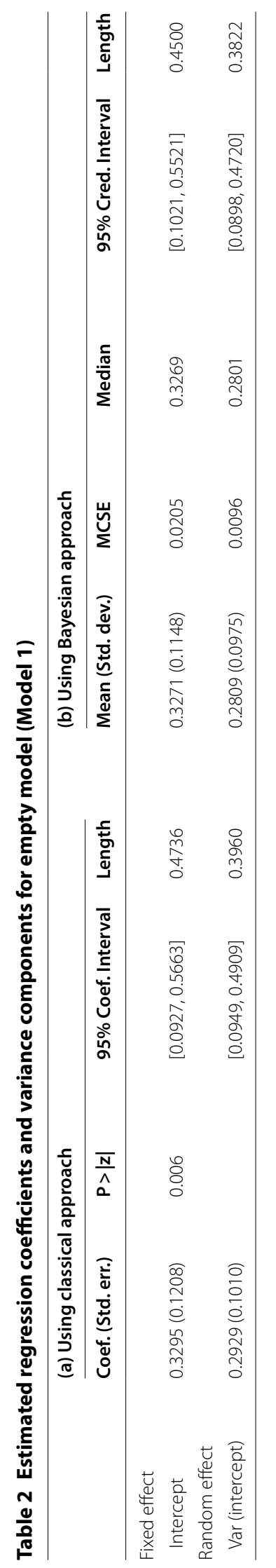




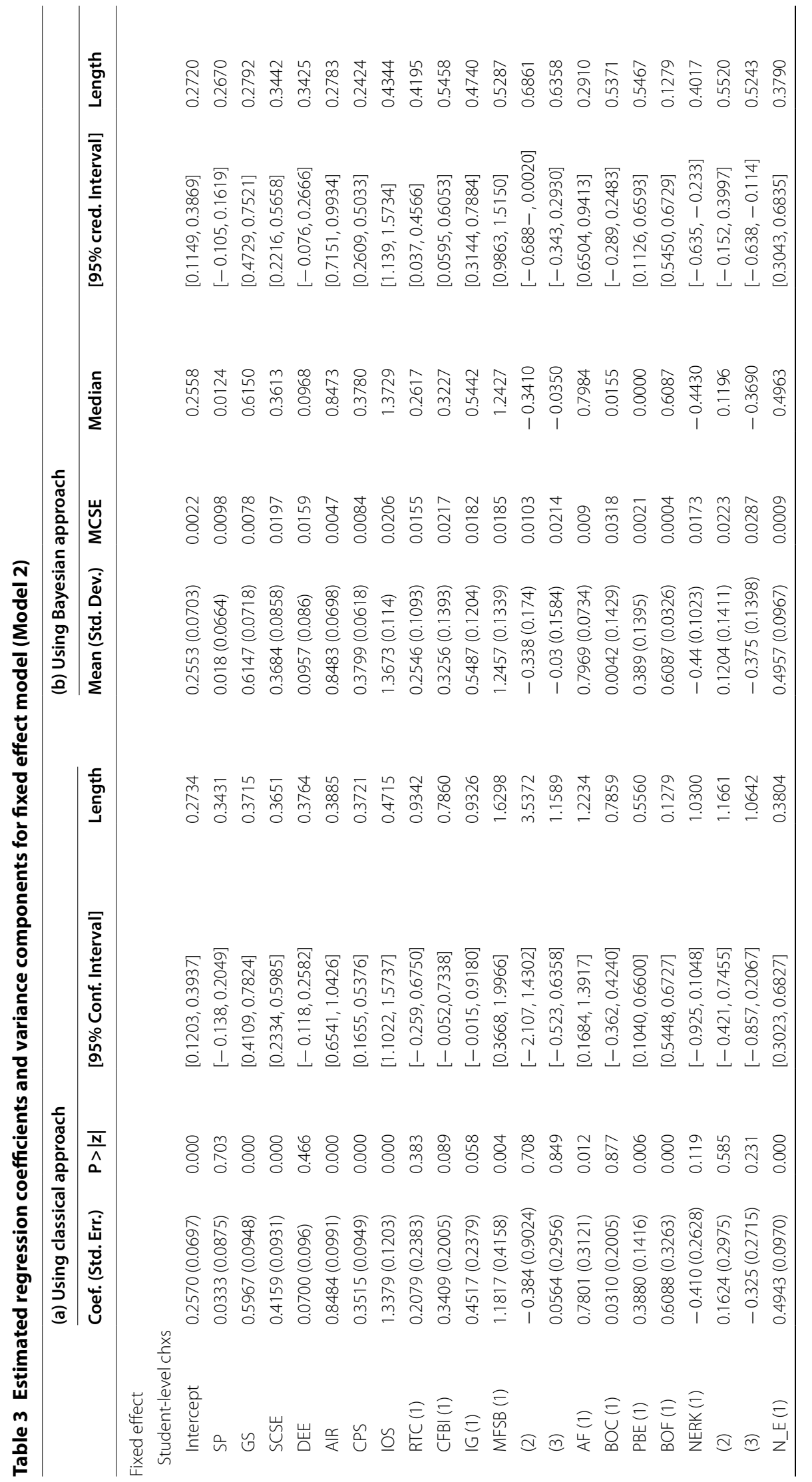




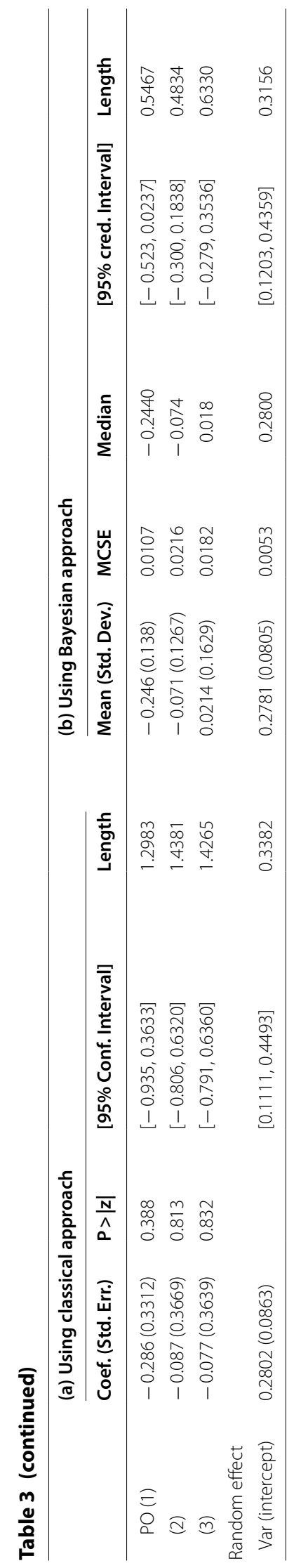


representing variation between university has decreased from 0.2929 in the empty model to 0.2802 in the fixed effect model and the significance of it indicates that there is a significant variation between student's entrepreneurial intention who placed in different university.

Table 3 shows us that there is clear difference between the values of $\beta$ coefficients of covariates in the model which estimated by classical and Bayesian approach. When Bayesian multilevel effects have not been taken into consideration as compared to classical approach, the $\beta$ coefficients have been underestimated or overestimated for the covariates. For instance, for the variables goal setting (GS) and information and opportunity seeking (IOS), the $\beta$ coefficients of the multilevel model estimated by classical approach have been underestimated by almost $3 \%$ and $2 \%$ respectively. On the contrary, the $\beta$ coefficients for the covariates, systematic planning (SP) and self-confidence and self-esteem (SCSE) factor score, the $\beta$ coefficients of the multilevel model using classical approach has been overestimated by $85 \%$ and $13 \%$ respectively. Hence $\beta$ coefficients are distorted somewhat in both directions either in over or under direction from the true value when Bayesian multilevel effects are not taken into consideration in modeling.

\section{Random effect model (Model 3)}

Random effect model allows the effect that the coefficient of the explanatory variable to vary from cluster to cluster. In this model, we considered student level variables (at level 1) and university level variables (at level 2). In the model that included both student and university characteristics (Model 3), ten of the 18 student characteristics were significantly associated with the log-odds of entrepreneurial intention, while only one of the three university characteristics (EE) was significantly associated with the outcome [odds ratio $=0.9958,95 \%$ CI $(0.8619,1.1297)$ ] (Table 4). Neither business counseling [odds ratio $=0.9958,95 \% \mathrm{CI}(0.8619,1.1297)$ ] nor exchange of thoughts, ideas and experiences by invited guests [odds ratio $=1.0187,95 \%$ CI $(0.8836,1.1537)$ ] was significantly associated with student's entrepreneurial intention. This means that there is no significance difference between students who enrolled in those university that provide business counseling service and those university that didn't provide this service in their entrepreneurial intention. Also, there is no significant difference between student's who enrolled in those university that shares or exchanges thoughts, ideas and experiences by invited guests and those university who did not invite any guests for business discourse in their entrepreneurial intention. The intercept for this model was 0.2498 . Thus, at an average university (i.e., a university whose random effect was equal to zero), the probability of entrepreneurial intention for a student whose covariates were equal to zero was $\operatorname{expo}(0.2498) /[1+\operatorname{expo}(0.2498)]=0.562$. The results of random effect model are shown in Table 4.

In Table 5, the value of Var (intercept) and Var (EE) are the estimated variance of random effect intercept and slope of EE respectively. These estimated variances are significant suggesting that intercept and slope of EE vary significantly. So, there is a significant variation in the effect of EE across university in Ethiopia. The random intercept for jth university is $0.2498(0.0690)+\emptyset_{0 j}$ and their variance 0.2774 (std. error $=0.0796$ ). Thus, the value 0.2498 is the intercept for region $j$ with $\emptyset_{0 j}=0$ (i.e., the mean value of $\emptyset_{0 j}$ ). The 


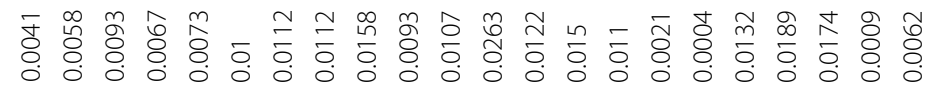

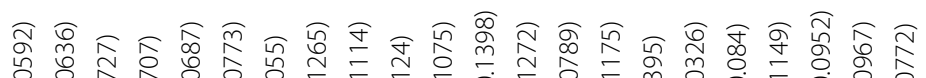

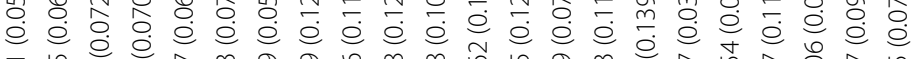

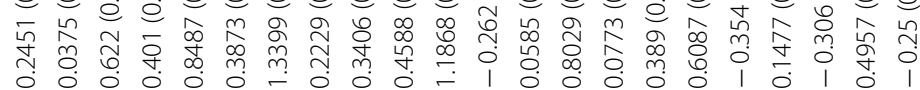

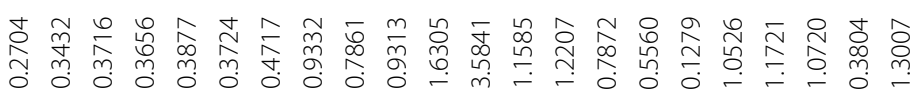

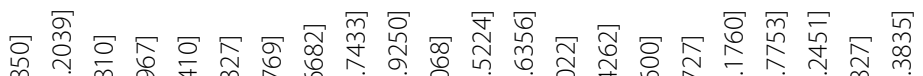
等

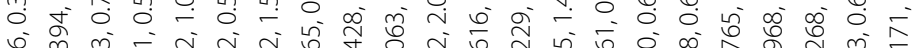

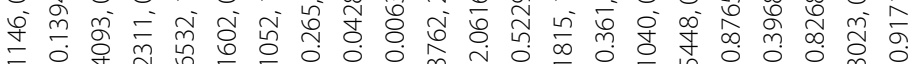

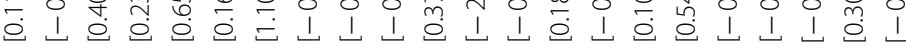

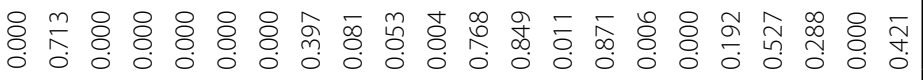

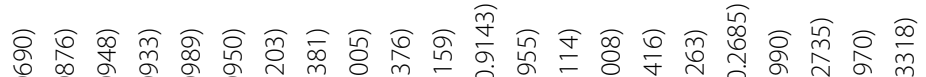

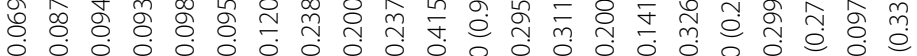
势 范等 $\frac{\sqrt[x]{\frac{x}{u}}}{\frac{\pi}{4}}$

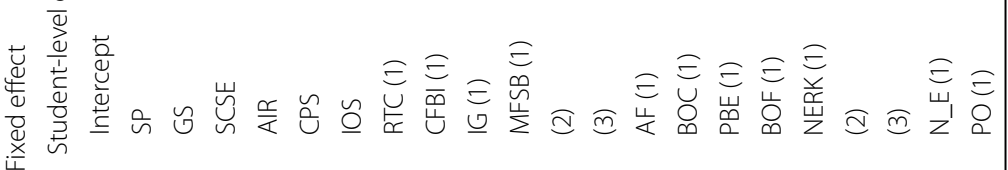




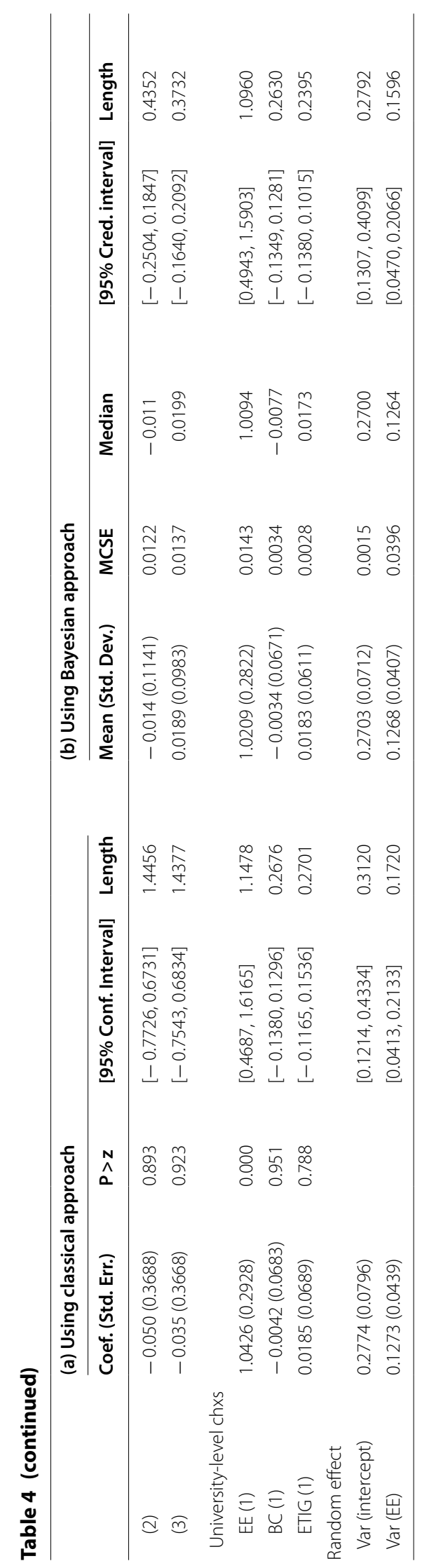


Table 5 Model comparison

\begin{tabular}{|c|c|c|c|}
\hline \multirow[t]{2}{*}{ Model } & \multicolumn{2}{|c|}{ Classical approach } & \multirow{2}{*}{$\begin{array}{l}\text { Bayesian approach } \\
\text { DIC }\end{array}$} \\
\hline & AIC & BIC & \\
\hline Empty model (Model 1) & 1257.775 & 1267.426 & 1253.195 \\
\hline Fixed effect model (Model 2) & 863.654 & 987.455 & 830.051 \\
\hline Random effect model (Model 3) & 859.075 & 968.591 & 828.661 \\
\hline
\end{tabular}

between-university variance of slope of EE is estimated to be 0.1273 (std. error 0.0439) and the individual university slopes of EE vary about with this amount.

\section{Model comparison}

For the aggregate analysis models, Akaike Information Criterion (AIC), Bayesian Information Criterion (BIC) and Deviance Information criteria (DIC) were applied as the evaluation measure. A smaller AIC, BIC and DIC indicate a better model fitting.

Table 5 displays the AIC, BIC and DIC for classical approach and Bayesian approach for each model. The findings indicate that random effect model (Model 3) is more plausible than Model 1 and Model 2. Bayesian approach is also more plausible than classical approach because DIC for Bayesian method demonstrated lowest value than AIC and BIC value for classical approach which denotes the better fits. This conclusion is similar with Pandey et al. [37], and Nasir and AI-Anber [33] study in which the Bayesian method is superior compared to maximum likelihood estimation.

To correctly interpret the parameter estimates related to predictors in a multilevel model, it is more meaningful to state that the individual estimates increase or decrease the log odds of the outcome. Another possibility is to convert the log odds into probabilities. We present $\beta$ coefficients for the models that estimated using ML and MCMC. It is observed that there exist significant differences between the $\beta$ coefficients of these two models for each of the explanatory variables. Also, the $\beta$ coefficients of the multilevel model using ML have been underestimated in comparison with the multilevel model using MCMC.

This study found evidence that entrepreneurial attitudes have significant influence on students' self-employment intention. The results conformed to the literatures that entrepreneurial attitude does have relationship with self-employment intentions. Based on Table 4, this research arrives at the following conclusions.

Entrepreneurship education improves motivation towards being entrepreneurial by inspiring students' personal attraction towards entrepreneurship and perceived behavioral control [12, 18, 41]. This is consistent with our findings. The result of this research indicates that students who placed in university that delivers entrepreneurship-oriented courses were $5.493(\mathrm{OR}=5.493)$ times higher than those students who placed in those university that didn't deliver entrepreneurship-oriented courses while controlling other variables. In conclusion, entrepreneurial education/training is positively related to selfemployment intention.

Students who came from business-owned family are more likely to have entrepreneurial intention compared to students who came from non-business-owned families. On the contrary, students who have business-owned colleagues are not significantly 
different from students who do not have business-owned colleagues. Table 4 tells us that students who came from business-owned families were $25.4 \%(\mathrm{OR}=1.838)$ more likely to have entrepreneurial intention compared to students who came from non-businessowned families. The reason might be that they may have prior business experience from families. The experience gained from their family member may influence the students' engagement in entrepreneurship. This is in agreement with the findings in other studies $[10,14,40,41]$. Similarly, the odd of entrepreneurial intention of students who have prior business experience from their family was $47.6 \%$ more likely to have entrepreneurial intention than students who have no any prior business experience from their family controlling other variables.

Access to finance is also a contributing risk factor for student's entrepreneurial intention. The odd of entrepreneurial intention of students who have access to finance/capital was about $23.2 \%(\mathrm{OR}=2.232)$ times higher than the odd of entrepreneurial intention of students who do not have access to capitals controlling for other variables in the model. Meanwhile, profession of parents is found to be insignificant for entrepreneurial intention. Intention of students in which their family livelihood is agriculture is not significantly different from governmental employee families. Similarly, students who came from government employee family are not significantly different from students came from private business-owned family in their entrepreneurial intention, etc.

The need of student on self-employment can be achieved through effective communication whereby information is captured properly and feedback is provided. This research comes up with the evidence that there is a significant difference in entrepreneurial intention status of students between information and opportunity seekers and non-seekers. The seekers have high intention $(\mathrm{OR}=3.818)$ to be entrepreneurs than non-seekers. Other researchers also pointed out that students who seek information and opportunity are more likely to be self-employed than non-seekers [20].

As expected, students who gather, process, and use information are more likely to start and engage in entrepreneurship and stay ahead in business. Students who have intention in entrepreneurship can quickly see and seize opportunities. They do things before circumstances force them to do. If a student has an intention to be self-employed, then he/ she always wants to learn things that will help him/her to grow business. On the other hand, there is no significant difference between students who know a number of entrepreneurs and students who do not know any entrepreneurs. Similarly, external discouraging factor is not a significant factor, i.e., no significant difference between students who are discouraged and non-discouraged by external factor on their self-employment intention.

Furthermore, creativity and problem-solving skills are also among the most important determinants of entrepreneurial intention among undergraduate university students. According to this research findings, students who have high level of creativity and problem-solving skills are more likely to engage in entrepreneurship activity $(\mathrm{OR}=1.472)$ than students who have low level of creativity and problem-solving skills. This finding is also in line with other previous studies [20, 26, 35]. These show that students who have high level of creativity and problem-solving skills have the highest intention to be self-employed. The reason might be a student with innovative mindset is more likely 
to initiate business and sustain it through continuous improvement. It means they find innovative ways to solve problem. They always look for new and better ways to do things.

The other qualities of successful entrepreneur are self-confidence and risk-taking commitment. Some studies have revealed that entrepreneurial intention increases if the individuals have high self-confidence and self-esteem [26]. Our findings are in agreement with this fact. Students who have high self-confidence and self-esteem are more likely $(\mathrm{OR}=1.493)$ to engage in entrepreneurship than from less confident students. The researchers believe that self-confident students have the ability to overcome business problems and succeed in the business activity. Most entrepreneurs start business because they like to be their own boss so that they are responsible for their own decisions. If a person is afraid of un-certainties, then he/she cannot be an entrepreneur. Unlike gamblers, entrepreneurs are not high-risk takers; they calculate their risks before taking action and place themselves in situations involving moderate risk.

Furthermore, this research revealed that other factors such as networking and professional contact, goal setting to their future career, and access to finance could also account for differences among the students on their attitude and intention for entrepreneurial activity. In analyzing the findings, this research found evidence that these factors have positive contribution to the entrepreneurial intention of students. From the result of the study, a student who establishes relationship, professional contacts and networks with business person had higher probability $(\mathrm{OR}=1.641)$ of being entrepreneurs than students who did not make any professional contacts and networks because an entrepreneur acts to develop and maintain business contacts by establishing good working relationship and uses deliberate strategies to influence others. The ability to establish and maintain positive relationship is crucial to the success of the students' business venture [43]. Hence, social relationship among formal inter-governmental organization networks to informal networks such as friendships and family ties affect decision-making and business performance. The social network stimulates business growth by reducing transaction costs, creating business opportunity, and generating knowledge spillover. Moreover, a student who sets meaningful and challenging goals for him/her has more likely to be entrepreneur than student who did not set goals.

Model diagnostic: Once the results of the model are computed, it is important to check for the convergence of Markov Chain Monte Carlo. Figure 1 illustrates the convergence of the Bayesian with non-informative prior using the Gelman-Rubin Convergence Diagnostic test. The histogram of MCMC residual is normal. The trace plot also indicates that convergence was achieved. Correlation becomes negligible after 10 periods. The algorithm converged after 100,000 iterations. To remove the autocorrelation and burning periods, a lag of 20 was considered and the first 35,000 iterations removed. The output of Gelman-Rubin convergence diagnostic test displays the red lines representing the $\hat{R}$. The graph shows that all the $\hat{R} \rightarrow 1$. Also, the blue and green lines which represent the within sample variance and the pooled posterior variance, are stationary. Thus, the Gelman-Rubin Convergence Diagnostic test suggests that the algorithm converges. 


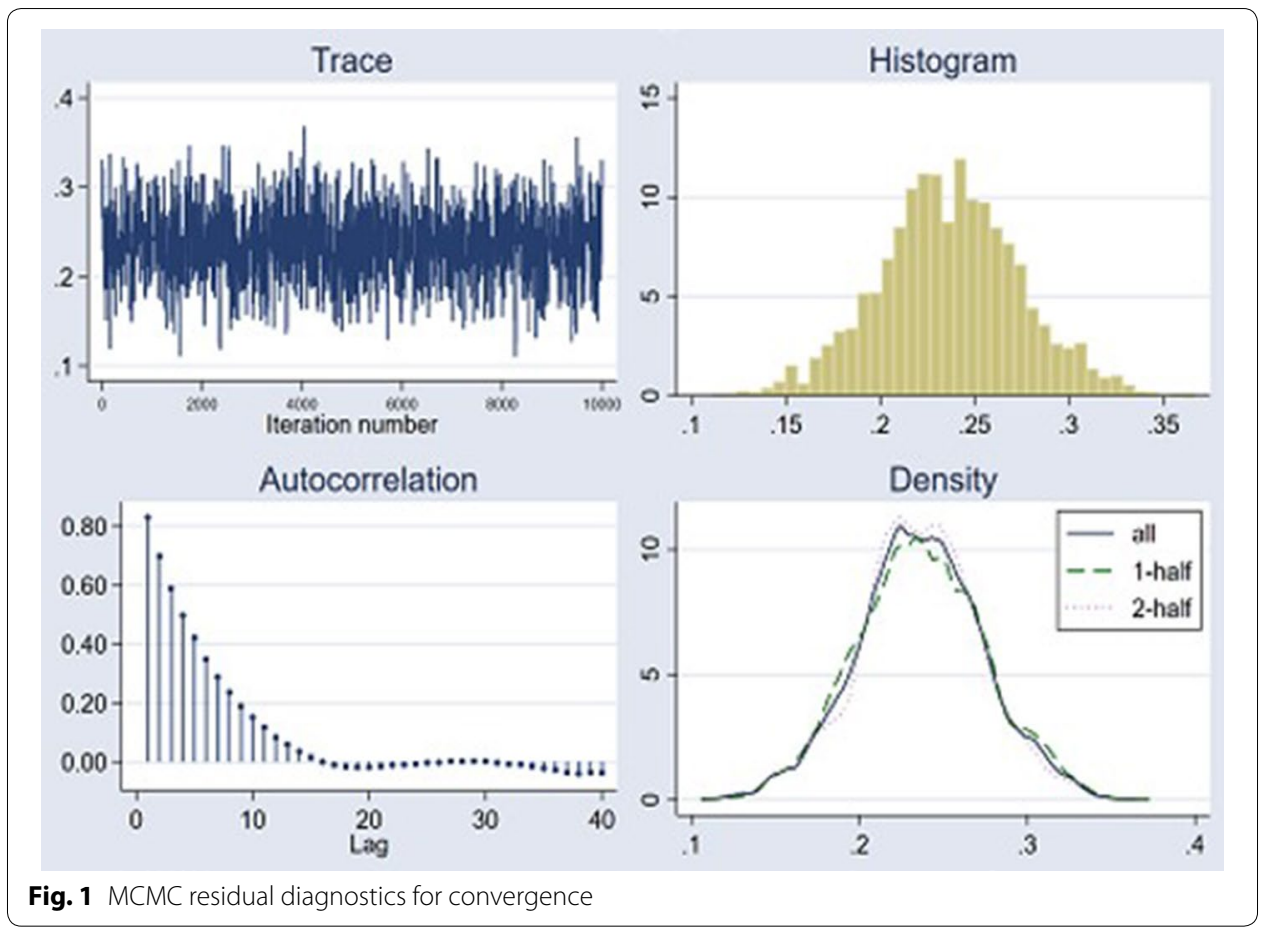

\section{Conclusion}

In this study, hierarchical logistic regression models were employed using classical approach and Bayesian approach. The purpose of the study was to evaluate and compare the behavior of maximum likelihood and Bayesian estimators to investigate the relationship between covariates and the response. Both point and interval estimation performances were investigated. The results reveal that lower standard errors of the estimated coefficients in the Bayesian logistic regression approach as compared to classical approach. Moreover, the results revealed that the length of the Bayesian credible interval is smaller than the length of the maximum likelihood confidence interval for all factors. In order to identify the most plausible method between Bayesian method and maximum likelihood estimation of the data, AIC, BIC and DIC are adopted in this paper. The result of the study depicts that the Bayesian method (low value of DIC) performs better and more efficient than maximum likelihood estimation. This research has arrived a conclusion that students who sought information and opportunity, took entrepreneurship education/training, set future goals, developed ability and skills on creativity and problem solving have a positive attitude towards entrepreneurial intention. In line to this, the government as well as the universities should design programs that facilitate entrepreneurship to change the mindset, attitude, and intention of those students who do not have an idea about entrepreneurship as a future career. Government should also build students' confidence to consider self-employment as their future career. Moreover, access to finance, professional contacts and networking with entrepreneurs, prior business experience, family background, and achievement and instrumental readiness also significantly predict the entrepreneurial intention. So, it is important to maintain and strengthen the cooperation and contacts between students, fund raisers, and entrepreneurs. From the above discussion, we conclude that lack of 
access to finance for startup, lack of appropriate education/training, low level of creativity and problem solving ability, low level of information and opportunity seeking, lack of prior business exposure, lack of business-owned family, lack of confidence, and low level of professional contacts and networking, low level of achievement and instrumental readiness, and lack of goal setting for their future career are some of important barrier factors that act to start a business by the students. These predictors have positive relationship with entrepreneurial intention.

Although a lot has been done to achieve the research objectives, there were some limitations and shortcomings. This research was conducted to investigate the cross-sectional effect of student level variables and university level variables on student's entrepreneurial intention. This research does not include the longitudinal effect of student level variables and University level variables on student's entrepreneurial intention. But the perception and attitude of students may be changed through time. Therefore, future research should be conducted to investigate not only the cross-sectional effect of student level variables and university level variables on student's entrepreneurial intention but also consider their longitudinal effect on entrepreneurial intention of students. The other limitation that I face during this research work is estimation of model parameters. It takes a lot of time for estimating model parameters in Bayesian approach.

\section{Abbreviations}

AIC: Akaike Information Criterion ; BIC: Bayesian Information Criterion; DIC: Deviance Information Criterion; OR: Odd ratio; MCMC: Markov Chain Monte Carlo; ML: Maximum likelihood.

\section{Acknowledgements}

The author would like to thank an anonymous referee for constructive comments to improve this work. The researcher would like to thank Bahir Dar Institute of Technology, University of Gondar and Debre Markos University for the permission to collect the required data. The author is also thankful to Students for providing the necessary data for the preparation of the paper. My gratitude and appreciation also go to our colleagues for their support and continued encouragement. Without their professional assistance and guidance, this project would not be realized.

\section{Authors' contributions}

MMA did the major tasks of the work. He designed, innovated and developed the overall conceptual framework for the analysis and interpretation of the data for the work. The author read and approved the final manuscript.

Funding

This work was financially supported by Bahir Dar Institute of Technology, Bahir Dar, Ethiopia.

Availability of data and materials

Data and material are available at any time. There are no restrictions on the development of data materials.

Competing of interests

The author declares that there have no competing interests.

Received: 11 November 2019 Accepted: 17 February 2020

Published online: 09 March 2020

\section{References}

1. Agresti M. An introduction to categorical data analysis. 2nd ed. New York: Wiley inter-science; 2007.

2. Autio E, Keelyey R, Klofsten M, Ulfstedt T. Entrepreneurial intent among students: testing an intent model in Asia, Scandinavia and The United States. Frontiers of entrepreneurship research. Wellesley: Babson College; 1997.

3. Ayalew MM, Zeleke SA. Modeling the impact of entrepreneurial attitude on self-employment intention among engineering students in Ethiopia. J Innov Entrep. 2018;7:8. https://doi.org/10.1186/s13731-018-0088-1.

4. Belas J, Klujnikov A. The most important attributes of entrepreneurs case study of the environment of Czech SMES. Int J Entrep Knowl. 2016:4(1):104-11.

5. Bezzina F. Characteristics of the maltese entrepreneur. Int J Arts Sci. 2010;3(7):292-312.

6. Breslow NE, Clayton DG. Approximate inference in generalized linear mixed models. J Am Stat Assoc. 1993;88:925.

7. Cochran WG. Sampling techniques. 3rd ed. New York: John Wiley \& Sons Inc.; 1979.

8. Corbeil RR, Searle SR. Restricted maximum likelihood (REML) estimation of variance components in the mixed model. Technometrics. 1976;18(1):31-8. 
9. Davey T, Plewa C, Struwig M. Entrepreneurship perceptions and career intentions of international student. J Educ Train. 2011;53(3):335-52.

10. Dohse D, Walter S. Knowledge Context and Entrepreneurial Intentions among Students. J Small Bus Econ Springer. 2012;39(4):877-95.

11. Douglas EJ, Shepherd AD. Self-employment as a career choice: attitudes, entrepreneurial intentions, and utility maximization. Entrep Theory Pract. 2002;26(3):81-90.

12. Dugassa T. Impact of entrepreneurship education on entrepreneurial intentions of business and engineering students in Ethiopia. Afr J Econ Manag Stud. 2012;3(2):258-77.

13. Fatoki O. Parental and gender effects on the entrepreneurial intention of university students in South Africa. Mediterr J Soc Sci. 2014;5(7):157-62.

14. Fitzsimmons JR, Douglass EJ. Entrepreneurial attitude and entrepreneurial intention: a cross-cultural study of potential entrepreneurs in India, China, Thiland and Austrialia. Wellesley: Babson-Kauffman Entrepreneurs Research Conference; 2005

15. Galloway L, Brown W. Entrepreneurship education at university: a driver in the creation of high growth fi rms? Educ Train. 2002;44(8/9):398-404.

16. Garavan TN, O'Cinneide B. Entrepreneurship education and training programmes: a review and evaluation —Part 1. J Eur Ind Train. 1994;18(8):3-13.

17. Gelman A, Carlin JB, Stern HS, Rubin DB. Bayesian data analysis. 2nd ed. Boca Raton: Chapman and Hall/CRC; 2004.

18. Gemechis T. Attitude of students for entrepreneurship in Addis Ababa University and Reft-Vally University. Eur J Bus Manag. 2007;6(4):350-63.

19. Goldstein H. Multilevel statistical models. 4th ed. Ltd: John Wiley and Sons; 2011.

20. Hamidi D, Wennberg D, Berglund H. Creativity in entrepreneurship education. J Small Bus Enterp Dev. 2008;15(2):304-20.

21. Herdjiono I, Puspa YH, Maulany G, Aldy BE. The Factors Affecting Entrepreneurship Intention. Int J Entrep Knowl. 2017;2(5):1-15.

22. Hilbe S. Logistic regression model. New York: Chapman and hall/CRC; 2009.

23. Hosmer A, Lemeshow M. Applied logistic regression. 2nd edn., Chicago: Wiley Publisher; 2000.

24. Hox JJ. Multilevel analysis: techniques and application. London: Lawrence Erlbaum Associates Inc; 2002.

25. Ibrahim AB, Soufani K. Entrepreneurship education and training in Canada: a critical assessment. Educ Train. 2002;44(8):421-30.

26. Ismail N, Jaffar N, Hooi TS. Using EAO model to predict the self-employment intentions among the universities' undergraduates in Malaysia. Int J Trade Econ Fin. 2013;4(5):90-7.

27. Kristiansen S, Indarti N. Entrepreneurial intention among Indonesian and Norwegian students. J Enterp Cult. 2004;12(1):55-78.

28. Kuratko DF. The emergence of entrepreneurship education: development, trends and challenges. Entrep Theory Pract. 2005;29:577-97.

29. Lindquist M, Sol J, Van Praag CM. Why do entrepreneurial parents have entrepreneurial children? J Labor Econ. 2015;33(2):269-96.

30. Longford NT. Random coefficient models. Oxford: Clarendom Press; 1993.

31. Meyers LS, Gamst G, Guarino AJ. Applied multivariate research: design and interpretation. Thousands: Sage; 2006.

32. Myung IJ. Tutorial on maximum likelihood estimation. J Math Psychol. 2003;47(1):90-100.

33. Nasir SA, Al-Anber NJ. A comparison of the Bayesian and other methods for estimation of reliability function for Burr-XII distribution. J Math Stat. 2012;8(1):42-8.

34. Nguyen C. Entrepreneurial intention of international business students in Viet Nam: a survey of the country joining the trans-pacific partnership. J Innov Entrep. 2017;6:7. https://doi.org/10.1186/s13731-017-0066-z.

35. Okpara FO. The value of creativity and innovation in entrepreneurship. J Asia Entrep Sustain. 2007:3(2):1-14.

36. Osborne JW. Advantages of hierarchical linear modeling. Pract Assess Res Eval. 2000;7(1):1-3.

37. Pandey BN, Dwivedi N, Bandyopadhyay P. Comparison between Bayesian and maximum likelihood estimation of scale parameter in Weibull distribution with known shape under linex loss function. J Sci Res. 2011;5(5):163-72.

38. Peugh JL. A practical guide to multilevel modeling. J School Psychol. 2010;48(1):85-112.

39. Raudenbush SW, Bryk AS. Hierarchical linear models: applications and data analysis methods. 2nd ed. Newbury Park: Sage; 2002.

40. Robson M. Determining entrepreneurial motivation of undergraduate student in Ethiopia higher learning institutions: the case of Haramaya University. Middle East Afr J Educ Res. 2015;14(4):214-25.

41. Sanditov B, Verspagen B. Multilevel analysis of the determinants of innovative entrepreneurship across Europe. Maastricht University. Paper presented at the final DIME conference. 2011; 4(2):6-8.

42. Snijders TAB, Bosker RJ. An introduction to basic and advanced multilevel modeling. SAGE publications Ltd, London United Nations Economic Commission for Africa, UNECA (2010): Economic Report on Africa 2010; 1999.

43. Turkina E, Assche AE, Kali R. Structure and evolution of global cluster networks: evidence from the aerospace industry. J Econ Geogr. 2016;16(6):1211-34.

44. Tyszka T, Cieślik J, Domuratc A, Macko A. Motivation, self-efficacy, and risk attitudes among entrepreneurs during transition to a market economy. The Journal of Socio-Economics. 2011;40(10):124-31.

45. Wang CK, Wong PK. Entrepreneurial interest of university students in Singapore. Technovation. 2004;24:163-72.

46. Yamane T. Statistics: an introductory analysis. 2nd ed., New York: Harper and Row; 1967.

47. Zimmerer TW, Scarborough NM. Essentials of Entrepreneurship and Small Business Management. 3rd ed. London: Prentice Hall; 2004.

\section{Publisher's Note}

